\title{
PIK3C3/VPS34 links T-cell autophagy to autoimmunity
}

\author{
Guan Yang ${ }^{1}$ and Luc Van Kaer (1)
}

Macroautophagy (called autophagy hereafter), a conserved cellular self-eating process that delivers cytoplasmic materials to lysosomes, has pleiotropic functions in immunological processes, including lymphocyte development, metabolism, and function ${ }^{1-4}$. Abnormalities in autophagy have been implicated in numerous immunemediated diseases ${ }^{5}$. For example, autophagy levels are markedly increased in activated $\mathrm{T}$ cells and play a critical role in the function of autoreactive $\mathrm{T}$ cells, which regulate the pathogenesis of inflammatory demyelinating diseases such as multiple sclerosis (MS) and its animal model, experimental autoimmune encephalomyelitis $(\mathrm{EAE})^{6}$.

The autophagy machinery consists of several sequential steps: initiation, nucleation, elongation, fusion, and degradation ${ }^{2}$. The phosphoinositide 3-kinase PIK3C3/ VPS34 forms a complex with BECN1/Beclin 1 and plays a central role in autophagosome nucleation ${ }^{7}$. To study the role of PIK3C3 in T-cell metabolism and function, we generated conditional knockout mice to selectively disrupt Pik3c3 in T cells, starting from their development in the thymus ${ }^{4}$. We first demonstrated that functional autophagy is severely blocked in Pik3c3-deficient T cells, which resulted in a substantial loss of circulating $\mathrm{T}$ cells and a reciprocal increase in the frequencies of other lymphoid cells in peripheral tissues ${ }^{4}$. Pik3c3-deficient $T$ cells also showed increased apoptosis, impaired ex vivo $\mathrm{T}$-cell receptor-induced proliferation, and defective $\mathrm{CD} 4^{+}$ $\mathrm{T}$ cell-mediated immune responses to the model antigen ovalbumin ${ }^{4}$. These findings thus revealed a critical role for PIK3C3 in T-cell homeostasis and function.

As autophagy captures and degrades cytoplasmic components for cellular metabolic processes, it is linked with T-cell metabolism. Our recent publication ${ }^{8}$ reported that Pik3c3-deficient $\mathrm{T}$ cells exhibit impaired cellular

\footnotetext{
Correspondence: Luc Van Kaer (luc.van.kaer@vumc.org)

${ }^{1}$ Department of Pathology, Microbiology and Immunology, Vanderbilt

University School of Medicine, Nashville, TN 37232, USA
}

metabolism, characterized by suppressed oxidative phosphorylation and abated glycolysis upon activation. Pik3c3deficient $\mathrm{CD} 4^{+} \mathrm{T}$ cells also exhibited a deficit in $\mathrm{T}$ helper 1 cell differentiation. As a result, $P i k 3 c 3$-deficient animals were resistant to EAE induced by active immunization with myelin oligodendrocyte glycoprotein (MOG) peptide. To dissect the effects of Pik3c3-deficiency on T-cell development and homeostasis versus $\mathrm{T}$-cell function, we

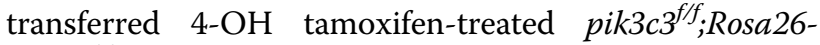
$\mathrm{CreER}^{T 2+}$ cells derived from MOG-immunized animals to allelically marked wild-type (WT) animals. Mice that received Pik3c3-deficient T cells were protected, whereas animals that received $P i k 3 c 3$-sufficient $\mathrm{T}$ cells developed signs of EAE. This EAE resistance was associated with reduced MOG-specific IFN- $\gamma$ and IL-17A production. These findings are consistent with our previous data with the model antigen ovalbumin ${ }^{4}$, indicating defective in vivo antigen-specific $\mathrm{CD} 4^{+} \mathrm{T}$-cell responses in the absence of PIK3C3.

Emerging evidence has revealed that components of the autophagy machinery can mediate non-autophagic functions ${ }^{9}$. The BECN1-PIK3C3 complex is shared by the canonical autophagy pathway, LC3-associated phagocytosis $(\mathrm{LAP})^{10}$, and LC3-associated endocytosis $(\mathrm{LANDO})^{11}$. In an effort to explore the relevant pathway responsible for the effects of $\mathrm{T}$ cell-specific Pik3c3-deficiency on EAE, we evaluated mice lacking RUBCN/ RUBICON, which is an essential component for LAP and $\mathrm{LANDO}^{11}$, but is not required for canonical autophagy $^{11,12}$. We found that all rubcn ${ }^{-1-}$ mice were equally susceptible as compared to WT control mice in developing EAE. These results indicated that the protection against EAE of mice with T cell-specific deletion of Pik3c3 was most likely unrelated to defective noncanonical autophagy. Nevertheless, these results cannot exclude the possibility that resistance to EAE in mice with $\mathrm{T}$ cellspecific deletion of Pik3c3 is due to defects in cellular

(c) Open Access This article is licensed under a Creative Commons Attribution 4.0 International License, which permits use, sharing, adaptation, distribution and reproduction in any medium or format, as long as you give appropriate credit to the original author(s) and the source, provide a link to the Creative Commons license, and indicate if changes were made. The images or other third party material in this article are included in the article's Creative Commons license, unless indicated otherwise in a credit line to the material. If material is not included in the article's Creative Commons license and your intended use is not permitted by statutory regulation or exceeds the permitted use, you will need to obtain permission directly from the copyright holder. To view a copy of this license, visit http://creativecommons.org/licenses/by/4.0/. 


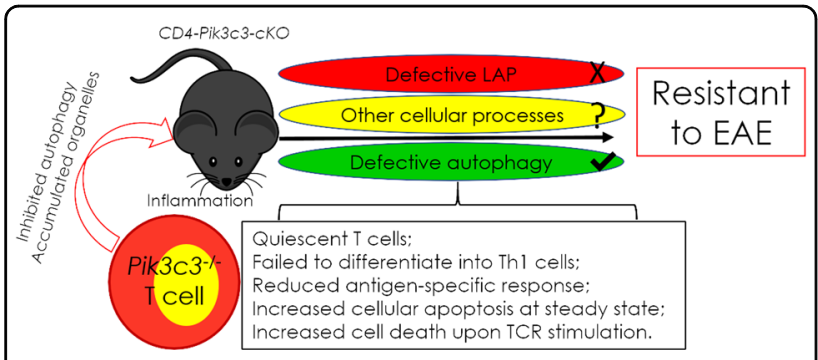

Fig. 1 Schematic diagram of EAE resistance in pik3c3 ${ }^{f / f} ; \mathrm{Cd} 4-\mathrm{Cre}$ mice. Ablation of Pik3c3 in T cells alters the phenotype and function of thesecells, leading to EAE resistance in CD4-Pik3c3-cKO mice. This EAE resistance is most likely dependent on defective canonical autophagy and possibly other cellular processes, but not the noncanonical autophagy pathway called LAP. CKO conditional knockout; TCR T cell receptor.

processes other than autophagy such as endocytosis and intracellular vesicular trafficking that also involve $\mathrm{PIK} 3 \mathrm{C} 33^{13}$.

Autophagy also regulates $\mathrm{CD} 8^{+} \mathrm{T}$-cell responses ${ }^{14,15}$. Our study further showed that $P i k 3 c 3$-deficiency in $\mathrm{CD} 8^{+}$ $\mathrm{T}$ cells has limited effects on clearing tumor metastases, although its underlying mechanisms remain unclear. It is possible that $P i k 3 c 3$ ablation caused dynamic changes in $\mathrm{CD}^{+}$effector T cells, NK cells, B cells, iNKT cells, and Tregs $^{4}$, which together contributed to the unaltered susceptibility to tumor metastases. Collectively, these data suggest that autophagy plays differential roles in $\mathrm{CD} 4^{+}$ and $\mathrm{CD} 8^{+} \mathrm{T}$ cells.

In conclusion, our data demonstrated that PIK3C3 is critical for $\mathrm{CD}^{+}{ }^{+} \mathrm{T}$-cell metabolism and $\mathrm{CD} 4^{+} \mathrm{T}$ cellmediated EAE development (Fig. 1). These findings link autophagy and T-cell pathogenicity and identify $\mathrm{T}$-cell autophagy as a major player in driving autoreactive $\mathrm{CD} 4^{+}$ $\mathrm{T}$ cell-mediated central nervous system pathology. These findings also suggest that the immunomodulatory properties of PIK3C3 can be harnessed for the development of novel therapies for autoimmune diseases. Future studies should explore the non-autophagic functions of the autophagy machinery in the pathogenesis and treatment of autoimmune diseases.

\section{Acknowledgements}

Work in the authors' lab was supported by grants from the NIH (Al139046 to L. V.K.) and the National Multiple Sclerosis Society (60006625 to L.V.K.).

\section{Conflict of interest}

The authors declare that they have no conflict of interest.

\section{Publisher's note}

Springer Nature remains neutral with regard to jurisdictional claims in published maps and institutional affiliations.

Received: 14 April 2020 Revised: 27 April 2020 Accepted: 28 April 2020 Published online: 07 May 2020

\section{References}

1. Dowling, S. D. \& Macian, F. Autophagy and T cell metabolism. Cancer Lett. 419, 20-26 (2018).

2. Yang, G., Driver, J. P. \& Van Kaer, L. The role of autophagy in iNKT cell development. Front. Immunol. 9, 2653 (2018).

3. Parekh, V. V. et al. Autophagy-related protein Vps34 controls the homeostasis and function of antigen cross-presenting $\mathrm{CD} \mathrm{a}^{+}$dendritic cells. Proc. Natl Acad. Sci. USA 114, 6371-6380 (2017).

4. Parekh, V. V. et al. Impaired autophagy, defective T cell homeostasis, and a wasting syndrome in mice with a T cell-specific deletion of Vps34. J. Immunol. 190, 5086-5101 (2013).

5. Klionsky, D. J. Autophagy participates in, well, just about everything. Cell Death Differ. 27, 831-832 (2020).

6. Van Kaer, L., Postoak, J. L., Wang, C., Yang, G. \& Wu, L. Innate, innate-like and adaptive lymphocytes in the pathogenesis of MS and EAE. Cell Mol. Immunol. 16, 531-539 (2019)

7. Axe, E. L. et al. Autophagosome formation from membrane compartments enriched in phosphatidylinositol 3-phosphate and dynamically connected to the endoplasmic reticulum. J. Cell Biol. 182, 685-701 (2008).

8. Yang, G. et al. Autophagy-related protein PIK3C3NPS34 controls T cell metabolism and function. Autophagy. https:/doi.org/10.1080/15548627.2020. 1752979 (2020).

9. Galluzzi, L. \& Green, D. R. Autophagy-independent functions of the autophagy machinery. Cell 177, 1682-1699 (2019).

10. Boyle, K. B. \& Randow, F. Rubicon swaps autophagy for LAP. Nat. Cell Biol. 17, 843-845 (2015).

11. Heckmann, B. L. et al. LC3-associated endocytosis facilitates beta-amyloid clearance and mitigates neurodegeneration in murine Alzheimer's disease. Cell 178, 536-551 (2019).

12. Martinez, J. et al. Molecular characterization of LC3-associated phagocytosis reveals distinct roles for Rubicon, NOX2 and autophagy proteins. Nat. Cell Biol. 17, 893-906 (2015).

13. Backer, J. M. The regulation and function of class III PI3Ks: novel roles for Vps34. Biochem. J. 410, 1-17 (2008)

14. Puleston, D. J. et al. Autophagy is a critical regulator of memory CD8(+) T cell formation. elife 3. https://doi.org/10.7554/eLife.03706 (2014).

15. $\mathrm{Xu}, \mathrm{X}$. et al. Autophagy is essential for effector $\mathrm{CD} 8(+) \mathrm{T}$ cell survival and memory formation. Nat. Immunol. 15, 1152-1161 (2014). 